\title{
Formación afectiva en la educación parvularia de Chile
} Affective formation in the Preschool Education of Chile

\section{Formação Afetiva em Educação Pré-escolar no Chile}

\author{
ISSN 1688-9304 - DOI: https://doi.org/10.18861/cied.2019.10.2.2907
}

Felipe Mujica Johnson*1

https://orcid.org/0000-0002-6956-2357

Maritza Angélica Toro Oyarzún**2

https://orcid.org/0000-0002-5899-3418

Fecha de recibido: 07/02/2019

Fecha de aprobado: 04/04/2019

\section{Resumen}

El currículum de educación preescolar en Chile propone una educación integral del alumnado, por tanto el currículo de este ciclo educativo contiene diferentes objetivos de aprendizaje afectivo que refieren a las emociones, las actitudes o los intereses del alumnado. Entre los antecedentes teóricos del tema destaca una propuesta basada en la teoría del bienestar subjetivo. Sin embargo, la formación afectiva requiere también ser integrada a la educación moral. Por esa razón la finalidad de este estudio es analizar los objetivos de aprendizaje del ámbito afectivo en el currículo de educación parvularia de Chile en función de la formación moral del alumnado. La metodología responde al enfoque cualitativo, con un diseño de estudio documental, de modo que se analizaron todos los objetivos de aprendizaje del currículo preescolar. Los datos fueron sometidos a un análisis de contenido deductivo-inductivo, con la utilización del programa Atlas.ti versión 7.5. Los resultados indican que existen objetivos de aprendizaje del ámbito afectivo planteados desde una perspectiva abierta y contextualizada que favorecen una comprensión crítica de la afectividad. Así, se plantean aprendizajes coherentes tanto con una educación emocional situada y flexible como con los intereses personales. Desde esta perspectiva se acepta con normalidad el afecto tanto positivo como negativo para el bienestar subjetivo. Pero también existen objetivos que responden a una perspectiva cerrada y estandarizada en la que solo se promueve el afecto positivo para el bienestar subjetivo, desconociendo la función del afecto negativo para el bienestar subjetivo o la posibilidad de percibir afectos diferentes a los que propone el currículum. Finalmente, se concluye que el currículo exige al alumnado preescolar experimentar emociones positivas para el bienestar subjetivo ante ciertos contenidos curriculares, ignorando que en esencia las emociones no se aprenden porque son respuestas ante ciertos aprendizajes de diferentes ámbitos, como el de la formación moral.

Palabras clave: emoción, educación preescolar, bienestar, currículum, educación moral.

\section{Abstract}

The curriculum of preschool education in Chile proposes a comprehensive education for students. Therefore, the curriculum of this educational cycle contains different goals of affective learning, which refer to the emotions, attitudes or interests of students. Among the theoretical background of the subject, a proposal based on the theory of subjective well-being stands out. However, emotional formation also requires being integrated into 
moral education. For such reason, the objective of this study is to analyze the learning objectives of the affective field in the curriculum of Early Childhood Education of Chile, based on the moral formation of the students. The methodology responds to the qualitative approach, with a documentary study design, so that all the learning objectives of the preschool curriculum were analyzed. Data were subjected to an analysis of deductiveinductive content, with the use of the Atlas.ti program, version 7.5. The results indicate that there are learning objectives of the affective field raised from an open and contextualized perspective, which favor a critical understanding of affectivity. Thus, coherent learning with a situated and flexible emotional education, as well as personal interests, are proposed. From this perspective, both positive and negative affection for subjective well-being are accepted normally. But there are also objectives that respond to a closed and standardized perspective, which only promotes positive affection for subjective well-being, ignoring the role of negative affection for the subjective well-being or the possibility of perceiving other kinds of affection that differ from those proposed by the curriculum. Finally, it is concluded that the curriculum requires preschool students to experience positive emotions for subjective wellbeing before certain curricular contents, ignoring that in essence emotions are not learned, because they are responses to certain learnings from different areas, such as moral formation.

Keywords: emotion, preschool education, well-being, curriculum, moral education.

\section{Resumo}

O currículo de educação pré-escolar no Chile propõe uma educação integral dos alunos. Portanto, o currículo desse ciclo educacional contém diferentes objetivos de aprendizado afetivo, que referem a emoções, atitudes ou interesses dos alunos. Entre os fundamentos teóricos do assunto, é de salientar uma proposta baseada na teoria do bem-estar subjetivo. No entanto, a formação afetiva também precisa ser integrada à educação moral. Por esse motivo, o escopo dessa pesquisa é analisar os objetivos de aprendizado do âmbito afetivo no currículo de educação pré-escolar do Chile, com base na formação moral dos alunos. A metodologia responde a uma abordagem qualitativa, com desenho de estudo documental, para que todos os objetivos de aprendizado do currículo préescolar sejam analisados. Os dados foram submetidos à análise de conteúdo dedutivoindutivo, utilizando o programa Atlas.ti, versão 7.5. Os resultados indicam que existem objetivos de aprendizado no âmbito afetivo estabelecidos sob uma perspectiva aberta e contextualizada, que favorecem uma compreensão crítica da afetividade. Assim, é gerado um aprendizado coerente tanto com uma educação emocional situada e flexível, quanto com interesses pessoais. Nessa perspectiva, normalmente são aceitos afetos positivos e negativos para o bem-estar subjetivo. Mas também existem objetivos que respondem a uma perspectiva fechada e padronizada, na qual apenas o afeto positivo é promovido para o bem-estar subjetivo, ignorando a função do afeto negativo para o bem-estar subjetivo ou a possibilidade de perceber afetos diferentes dos propostos pelo currículo. Finalmente, conclui-se que o currículo exige que os alunos da pré-escola experimentem emoções positivas para o bem-estar subjetivo diante de determinados conteúdos curriculares, ignorando que, em essência, as emoções não são aprendidas, porque são respostas a determinadosaprendizados de diferentes campos, como a formação moral.

Palavras chaves: emoção, educação pré-escolar, bem-estar, currículo, educação moral.

\section{Introducción}

Una adecuada formación escolar ha de mantener una equilibrada integración en la enseñanza de los ámbitos cognitivo, artístico, afectivo, moral y motor. En este sentido, abordar la dimensión socioafectiva en los objetivos verticales de aprendizaje (objetivos que derivan de los ámbitos y núcleos de aprendizaje, para ser concretados en cada 
nivel de transición) en el currículo de Educación Parvularia responde a una buena señal pedagógica que demuestra la intención de trascender las perspectivas tradicionales y hegemónicas implícitas en el currículo escolar (Coll, 1993; Carretero, 2000; Kirk y MacPhail, 2002; Sarramona, 2008; Unicef y Unesco, 2008; Murillo y Román, 2010; Toro, 2012; Toro y Valenzuela, 2012; Moreno, Gamboa y Poblete, 2014; Moreno, 2018). Entre los aspectos críticos de la perspectiva tradicional se destaca una visión positivista de la educación, la que otorga mayor importancia al ámbito cognitivo o también denominado intelectual. Esta situación genera un reduccionismo en torno al constructo de la calidad educativa debido a que atiende en forma superficial el contenido de los otros ámbitos educativos.

Con respecto a la dimensión afectiva, la misma ha sido conceptualizada por el principal organismo chileno encargado de la educación a nivel gubernamental como "un conjunto de emociones, estados de ánimo y sentimientos que permean los actos de las personas, incidiendo en el pensamiento, la conducta y la forma de relacionarse con uno mismo y con los demás" (Ministerio de Educación, 2013, p. 6). Esta definición es significativa para el presente estudio ya que el mismo se enmarca en el contexto educativo de Chile. En tanto producto de la globalización también se encuentra asociado a las perspectivas pedagógicas que predominan en la región iberoamericana. Al respecto, en las últimas dos décadas se ha elaborado una propuesta educativa que ha tenido bastante alcance en los países de aquella región, la que fomenta la educación emocional en el ámbito escolar y universitario con énfasis en la formación del profesorado (Bisquerra, 2003; Bisquerra, 2005; Bisquerra et al., 2016; Bisquerra y Hernández, 2017; Bisquerra y Filella, 2018). Esta propuesta encuentra sus cimientos epistemológicos en la teoría de la inteligencia emocional (IE) y la psicología positiva (Prieto, 2018), por lo que se orienta a promover el bienestar subjetivo (BS) en los educandos (Mujica, 2018a). Sin embargo, esta propuesta ha sido criticada por su perspectiva acrítica con el valor de las emociones (Marina, 2005; Prieto, 2018; Mujica, 2018b; Mujica, Inostroza y Orellana, 2018), y que manifiesta que el desarrollo de emociones positivas para el BS en el proceso de enseñanza-aprendizaje es algo beneficioso para el alumnado y para el proceso pedagógico pero que debe estar guiado por un marco filosófico-ético de la educación (Marina, 2005), lo cual desde una perspectiva histórico-cultural exigiría "Relativizar el valor positivo o negativo de las emociones, ya que una emoción podría ser valorada en los siguientes cuatro escenarios: ser positiva para el BS y negativa a nivel sociocultural; ser positiva para el BS y positiva a nivel sociocultural; ser negativa para el BS y positiva a nivel sociocultural; ser negativa para el BS y negativa a nivel sociocultural". (Mujica, Orellana y Canepa, 2018, p. 4).

Cabe precisar que la emoción es definida como "una respuesta afectiva intensa y breve que se produce en respuesta a un suceso o una situación determinada, y que va asociada a cambios corporales específicos y está relacionada con lo que es importante para nosotros" (Alonso, 2017, p. 17). Y estas respuestas afectivas se encuentran asociadas a la moralidad de cada persona (Maturana y Nisis, 1997; Hersh, Reimer y Paolitto, 2002; Scheler, 2005) que se comienza a formar desde la infancia (Kay, 1976; Kohlberg, 1976; Hersch et al., 2002; Elorrieta-Grimalt, 2012). Así surge el concepto de emociones morales, las que pueden cumplir la función de orientar la conducta humana hacia el buen o mal comportamiento, dependiendo de los valores que se hayan aprehendido. Entre aquellas emociones se encontraría "la alegría del deber cumplido, el temor de obrar mal, la vergüenza y los remordimientos por alguna culpa, el arrepentimiento de una falta (...)" (Quintana, 1995, p. 15). Y en sentido contrario, cuando una persona es gobernada por sentimientos negativos como el odio y, por consiguiente, el rechazo hacia el bienestar de los demás, existiría la "alegría en el dolor y el daño y se produce la serie de los sentimientos heteropáticos de valor negativo: envidia, alegría del mal ajeno, etc." (Scheler, 2005, p. 204). 
En este sentido sería incorrecto pensar que la educación debe suscitar emociones positivas y prescindir de las emociones negativas para el BS, ya que ambas cumplen importantes funciones que denotan el vínculo emocional que cada persona tiene con el mundo (Prieto, 2018). Por ejemplo, que el alumnado sienta tristeza ante el dolor ajeno demostraría el aprendizaje de la empatía. Por consiguiente, sería un absurdo homologar el valor de las emociones a un valor pedagógico, como por ejemplo, considerar que la alegría o la diversión siempre son positivas en el proceso educativo porque favorecen el BS, debido a que las emociones en sí mismas no tienen un valor moral intrínseco, pudiendo manifestarse ante una acción moral correcta o incorrecta (Steinfath, 2014).

Este análisis se encuentra muy bien reflejado en un estudio que abordó la violencia escolar e identificó la forma en que los estudiantes que ejercían la violencia contra sus compañeros sentían diversión mientras realizaban aquellos actos, favoreciendo su BS por medio del malestar subjetivo que provocaban a sus pares (Velázquez, 2005). Por consiguiente, las emociones del alumnado más allá de su valor positivo o negativo para el BS han de ser interpretadas como un aspecto esencial para la interacción social, ya que son "fenómenos de corta duración, relacionados con sentimientos, estimulación, intención y expresión, que nos ayudan a adaptarnos a las oportunidades y retos que afrontamos durante los sucesos significativos de la vida" (Reeve, 2010, p. 7). Es más, es muy necesario que en el proceso pedagógico los estudiantes estén dispuestos a percibir emociones negativas para su BS y que tanto el profesorado como los profesionales que apoyan la labor pedagógica deban cumplir la función de contener a los estudiantes ante los momentos de sufrimiento afectivo.

\section{Formación afectivo-social en la educación preescolar}

Según el actual currículo chileno la educación parvularia se orientaría a la formación integral de los preescolares, lo cual por supuesto incluiría la educación en el ámbito moral. Este planteamiento es coherente con los propósitos pedagógicos que se declaran en la propuesta curricular. Un propósito pedagógico sería el de "Propiciar el desarrollo de experiencias de aprendizaje que, junto con la familia, inicien a las niñas y los niños en su formación valórica y como ciudadanos, considerándolos en su calidad de sujetos de derecho, en función de la búsqueda de la trascendencia y el bien común". (Ministerio de Educación, 2018).

Aquella finalidad de incidir en la formación moral desde temprana edad es respaldada por diferentes especialistas que han investigado el desarrollo evolutivo del ser humano. Por su parte Hersh et al. (2002) destacan los estudios de Jean Piaget y Lawrence Kohlberg por su contribución teórica en torno al razonamiento moral en la infancia. Por su parte Piaget, tras sus indagaciones realizadas en torno al juicio moral del alumnado preescolar y escolar en diferentes actividades lúdicas, identifica que los niños entre 3-6 años se encuentran fuertemente marcados por el egocentrismo, lo cual coincide con las etapas primarias de su desarrollo cognitivo, que les dificulta comprender los significados en torno a las reglas y a la interacción social en los juegos sociomotores. Asimismo afirma que el "respeto por la ley del niño de seis años se basa en una comprensión de las reglas muy parcial y egocéntrica. Como quien está entrando en el mundo de la interacción social conscientemente" (p. 42). Así, señala que recién a esa edad el niño comenzaría a tomar conciencia de las autoridades pero no comprendería el motivo que fundamenta cada reglamento de los juegos sino que debe ser obedecido para responder bien a la autoridad. En concordancia con lo anterior Kay (1976) resume las comprobaciones de Piaget en torno 
al juicio moral, pues los niños en etapa preescolar presentan una "moralidad de compulsión, en que los juicios morales se basan en la autoridad externa y en una rígida interpretación de normas y reglamentos, y finalmente llega a una moralidad de cooperación en que los juicios se basan en consideraciones sociales" (p. 145). Posteriormente, y en base a estos planteamientos, Kohlberg $(1976,1992)$ desarrolla su propia teoría del desarrollo del juicio moral en la que establece tres niveles y seis estadios de desarrollo. El primer nivel, donde se encontrarían los niños preescolares por un factor evolutivo, fue denominado preconvencional, mientras que su primer estadio lleva por nombre moralidad heterónoma y el segundo individualismo. Este nivel estaría marcado por la fase egocéntrica que identificó Piaget, de modo que el alumnado se inclinaría por un buen comportamiento para evitar el castigo de las autoridades ya que no se considerarían los intereses ajenos antes que los propios.

Estos antecedentes confirmarían la dificultad que tendrá el alumnado para adaptarse a las conductas morales que requieran respetar los derechos ajenos, por lo que sería normal que el alumnado experimentase afectos negativos ante aquellas exigencias pedagógicas. En este sentido aquellas emociones negativas para el BS serían una resistencia subjetiva a modificar la moralidad egocéntrica, por lo que es inevitable realizar acciones que susciten aquellos afectos. No obstante, si aquellos procesos se refuerzan positivamente por medio de estímulos verbales o materiales, también se podrá suscitar un afecto positivo tras el buen obrar. Por lo tanto, cabría reconocer que tanto las emociones positivas como las negativas para el BS son relevantes en los procesos pedagógicos ya que las emociones cumplen una función psicosocial, por lo que ayudan a los estudiantes a integrarse en los grupos sociales y a construir su propia identidad (Guedes y Álvaro, 2010).

Para favorecer la comprensión de este tema, a continuación se presentarán tres ejemplos: a) Un alumno de 4 años que en su hogar ha aprendido a maltratar a los animales. Al tener como modelo a su hermano mayor ha intentado repetir esta conducta en su centro educativo con un animal que allí se encontraba. Es probable que, al impedir el docente tal situación y al dialogar con el alumno le suscite emociones negativas para su BS como enfado o frustración al no poder realizar una acción que dentro de su configuración moral y emocional estaba permitida.

b) Una alumna de 3 años, que no está acostumbrada a prestar sus juguetes. En el centro educativo deben compartirse los materiales de juego también con otros niños que no suelen querer compartir los materiales. Es probable entonces, que la niña sienta tristeza o enfado cuando alguien le arrebate un material o cuando el docente le solicite el material para compartirlo o guardarlo.

c) Un niño de 3 años y medio que se encuentra desarrollando una clase de estimulación motriz y por utilizar mal el material sufre un pequeño accidente que le causa dolor y lo hace llorar. Luego, el alumno siente miedo de realizar la misma acción arriesgada pues aprendió a asociar algunas acciones con sus consecuencias.

Frente a estos ejemplos, aquellas emociones negativas para el BS ¿eran innecesarias y hay que evitarlas? O, por el contrario, sí son situaciones inevitables que reflejan la configuración subjetiva-emocional (González, 2009) que cada alumno comienza a desarrollar a través de sus experiencias escolares. Tal como se ha expresado, aquellas emociones que producen malestar subjetivo son fundamentales para el desarrollo humano y han de ser interpretadas por el profesorado desde la complejidad que representan pero, asimismo, deben ser complementadas a través de principios morales con la finalidad de que el alumnado pueda desarrollar adecuados valores para la sociedad. De acuerdo con Maturana (1996), para 
identificar la emoción se debe atender a lo siguiente: si queremos conocer la emoción del otro debemos mirar sus acciones; si queremos conocer las acciones del otro, debemos mirar su emoción. Estas miradas solo son posibles en la medida en que no prejuzguemos lo que vamos a ver antes de mirar, y ese es un acto de sabiduría (p. 41).

En la Tabla 1 se presentan algunas de las posibles asociaciones entre las acciones, la moral y las emociones.

Tabla 1. Entrelazamiento de las acciones, la moral y la emoción

\begin{tabular}{|l|l|l|l|}
\hline Acción semi-contextualizada & Valor moral & $\begin{array}{l}\text { Posibles } \\
\text { emociones del } \\
\text { emisor }\end{array}$ & $\begin{array}{l}\text { Posibles emociones } \\
\text { del receptor }\end{array}$ \\
\hline $\begin{array}{l}\text { 1) Un niño de } 3 \text { años abraza a su } \\
\text { compañero y le regala un trozo de } \\
\text { colación. }\end{array}$ & Solidaridad & $\begin{array}{l}\text { Alegría, seguridad, } \\
\text { entusiasmo, } \\
\text { satisfacción }\end{array}$ & $\begin{array}{l}\text { Alegría, seguridad, } \\
\text { satisfacción, } \\
\text { tranquilidad, } \\
\text { vergüenza }\end{array}$ \\
\hline $\begin{array}{l}\text { 2) Una niña de cuatro años y } \\
\text { medio golpea a su compañero con } \\
\text { un juguete, por molestarla. }\end{array}$ & $\begin{array}{l}\text { Irresponsa- } \\
\text { bilidad }\end{array}$ & $\begin{array}{l}\text { Enfado, miedo, } \\
\text { inseguridad, } \\
\text { satisfacción, } \\
\text { vergüenza }\end{array}$ & $\begin{array}{l}\text { Tristeza, miedo, } \\
\text { enfado, inseguridad, } \\
\text { vergüenza, ansiedad }\end{array}$ \\
\hline $\begin{array}{l}\text { 3) Un niño de cinco años consigue } \\
\text { que uno de sus compañeros no se } \\
\text { integre a un juego grupal. }\end{array}$ & Egoísmo & $\begin{array}{l}\text { Diversión, miedo, } \\
\text { inseguridad, } \\
\text { satisfacción, } \\
\text { vergüenza }\end{array}$ & $\begin{array}{l}\text { Vergüenza, } \\
\text { frustración, } \\
\text { inseguridad, miedo, } \\
\text { enfado, indignación, } \\
\text { ansiedad }\end{array}$ \\
\hline $\begin{array}{l}\text { 4) Una niña de cuatro años le } \\
\text { solicita por favor a su compañera } \\
\text { que se levante, porque está encima } \\
\text { de una hoja suya, quien accede sin } \\
\text { problema. }\end{array}$ & Respeto & $\begin{array}{l}\text { Alegría, seguridad, } \\
\text { satisfacción, alivio, } \\
\text { gratificación }\end{array}$ & $\begin{array}{l}\text { Seguridad, } \\
\text { tranquilidad, } \\
\text { diversión, } \\
\text { satisfacción }\end{array}$ \\
\hline
\end{tabular}

Fuente: Elaboración propia

Tal como se ha planteado, estas asociaciones configuran una proyección cualitativa y flexible que contribuiría a comprender algunas de las funciones favorables de las emociones negativas para el BS en función de la formación moral. Por ejemplo, en los casos 2 y 3 de la Tabla 1 se han presentado dos situaciones indeseables desde el punto de vista moral y se ha consignado la posibilidad de que el niño sienta vergüenza de sus actos, lo cual podría suceder una vez que en forma autónoma tome conciencia de que esas acciones son incorrectas o luego de que el profesorado le ayude a reflexionar sobre la situación. Por lo tanto, durante el acto educativo que se desarrolla en los diferentes niveles educativos es inevitable que el alumnado experimente este tipo de emociones e, incluso, si se desea desarrollar la moral en los aprendices es inevitable que el profesorado suscite emociones negativas para el BS que ayuden al alumnado a abstenerse de ciertos actos o, a su vez, que promuevan que el alumnado no experimente emociones positivas para su BS cuando estas favorezcan un retroceso valórico.

Considerando estos antecedentes, el objetivo de este estudio es analizar los objetivos de aprendizaje (OA) referidos al ámbito afectivo del currículo de Educación Parvularia de Chile en función de la educación moral del alumnado. Por esa razón el análisis estará centrado 
en una interpretación crítica de la emoción que incluye una valoración no estandarizada de las emociones -valoradas desde diferentes perspectivas-, que podría incluir factores pedagógicos, psicológicos y filosóficos. En otras palabras, se consideraría tanto el bienestar subjetivo como la formación moral del alumnado, lo cual se enmarca en una perspectiva psicosocial. En sentido contrario, el análisis también incluye una perspectiva acrítica de las emociones, que las valora solamente desde una perspectiva individual, como lo es el bienestar subjetivo.

\section{Método}

Esta investigación responde a una metodología cualitativa con un enfoque interpretativo y un diseño de estudio documental (Moreno et al., 2014).

La muestra documental corresponde a las bases curriculares que rigen la Educación Parvularia de Chile (Ministerio de Educación, 2018), de las cuales se extrajeron 206 objetivos de aprendizaje que son los que "establecen los aprendizajes que se espera de los párvulos en cada nivel educativo" (Ministerio de Educación, 2018, p. 44). Aquellos objetivos corresponden a los siguientes tres ámbitos del currículo tanto del primer nivel (N1), como del segundo nivel (N2) y del tercer nivel (N3) de transición. Dichos ámbitos son: a) desarrollo personal y social; b) comunicación integral; y c) interacción y comprensión del entorno. En cuanto al análisis de datos se llevó a cabo un análisis de contenido que siguió la vía deductiva-inductiva (Osses, Ibañez y Sánchez, 2006), debido a que el proceso de codificación tuvo como punto de partida las siguientes dos categorías centrales: a) desarrollo crítico de la dimensión afectiva-social: objetivos de aprendizaje que contribuyen a la comprensión de las emociones y su coherencia relacional con el entorno; y b) desarrollo acrítico de la dimensión afectiva-social; objetivos que contribuyen a un adoctrinamiento emocional o estandarización afectiva ya que se establece una sola forma correcta de experimentar las emociones.

Para favorecer la codificación de los datos, la asociación categorial y la representación conceptual se ha utilizado el programa Atlas.ti versión 7.5. Para el rigor metodológico se ha aplicado el principio de saturación de datos (Onwuegbuzie, Dickinson, Leech y Zoran, 2011) y la fiabilidad inter-observadores a través de la concordancia consensuada de carácter cualitativo (García-Fariña, Jiménez y Anguera, 2016).

\section{Resultados}

El análisis de contenido, por la vía deductiva-inductiva, generó la producción de nueve subcategorías que responden al tipo de desarrollo afectivo-social que proponen. Dichas subcategorías presentan diferentes relaciones, de modo que en la Figura 1 se expone aquella red de asociaciones conceptuales que fue diseñada en el programa Atlas.ti. 


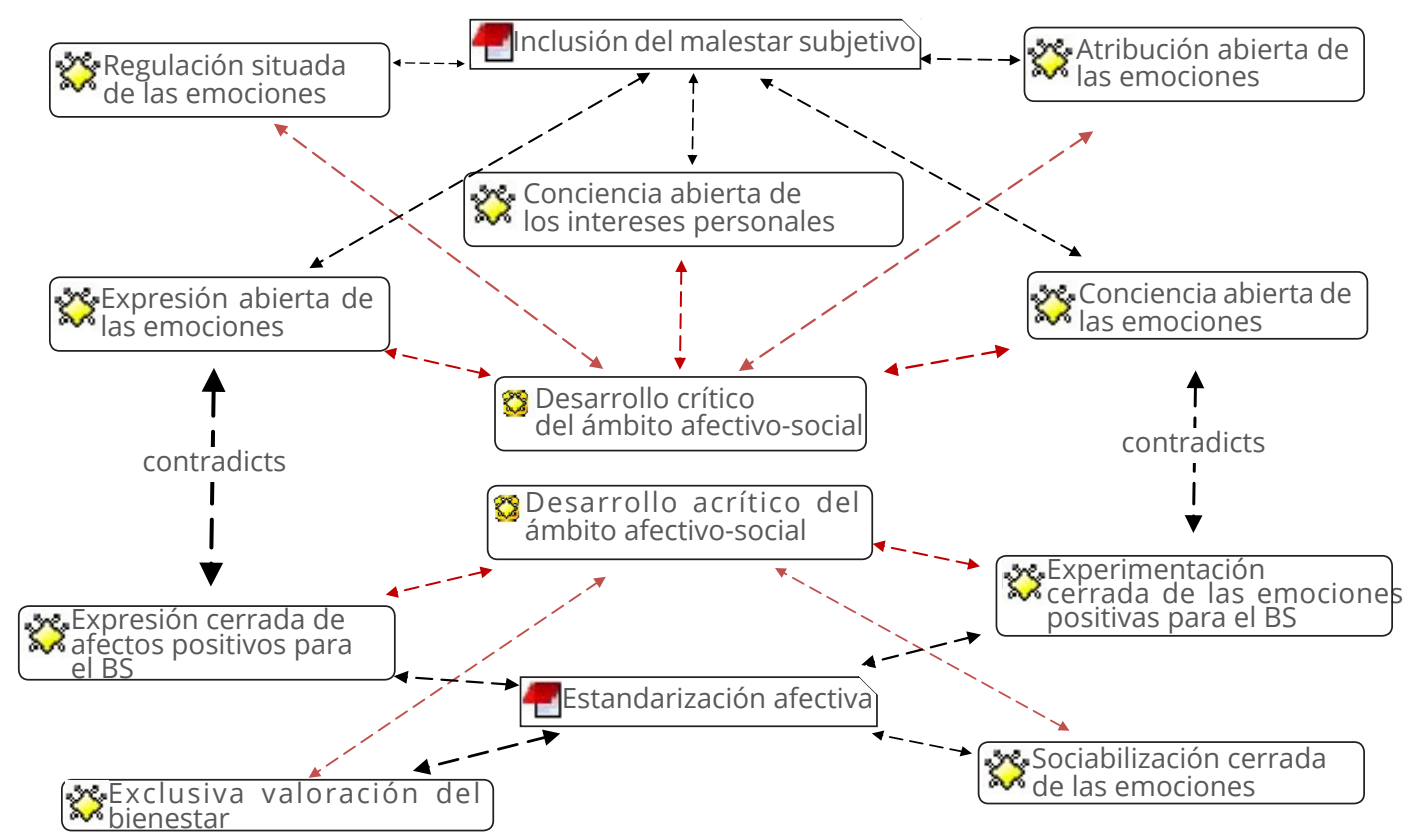

Figura 1. Red semántica sobre el desarrollo del ámbito afectivo-social.

A continuación se establece la presentación cualitativa de las subcategorías del estudio en función de sus categorías centrales, lo cual permite exponer el análisis interpretativo de los datos. Para aportar a la credibilidad de los hallazgos se incorporarán, en el relato, citas textuales de los objetivos extraídos de las bases curriculares de Educación Parvularia.

De la categoría desarrollo crítico del ámbito afectivo-social emergieron cinco subcategorías. La primera fue denominada conciencia abierta de las emociones porque incluye una percepción amplia de las emociones, tanto de las positivas como de las negativas para el $\mathrm{BS}$, propias y de las demás personas. Esto se expresa en el siguiente objetivo de aprendizaje del núcleo identidad y autonomía correspondiente al ámbito desarrollo personal y social. Dicho objetivo consiste en "reconocer en sí mismo, en otras personas y en personajes de cuentos, emociones tales como tristeza, miedo, alegría, pena y rabia" (OA3, N2).

La segunda subcategoría fue denominada expresión abierta de las emociones debido a que incluye objetivos que fomentan una amplia y diversa expresión de las emociones. Para representar esta idea se presenta un objetivo de aprendizaje del núcleo lenguajes artísticos, del ámbito comunicación integral, que consiste en "expresar corporalmente las emociones y sensaciones que le provocan algunas piezas musicales, bailando, cantando e intentando seguir el ritmo" (OA5, N1).

La tercera subcategoría fue denominada conciencia abierta de intereses personales porque incluye objetivos de aprendizaje que respetan la diversidad de preferencias del alumnado. Esta idea se expresa en el siguiente objetivo de núcleo identidad y autonomía, correspondiente al ámbito desarrollo personal y social y que consiste en "manifestar sus preferencias por algunas situaciones, objetos y juegos" (OA4, N1). 
La cuarta subcategoría fue denominada atribución abierta de emociones, fundamentada en objetivos que alientan al alumnado a identificar asociaciones entre las emociones y su entorno con el fin de favorecer la comprensión emocional. Un ejemplo es el objetivo del núcleo de convivencia y ciudadanía correspondiente al ámbito desarrollo personal y social y que consiste en "identificar objetos, comportamientos y situaciones de riesgo que pueden atentar contra su seguridad, su bienestar y el de los demás" (OA7, N2).

Para finalizar esta categoría central se presenta la quinta subcategoría, denominada regulación situada de las emociones porque incluye objetivos que exigen ajustar las emociones en función del contexto, es decir, en respuesta a una evaluación cualitativa de las situaciones pedagógicas. Un ejemplo es el siguiente objetivo del núcleo identidad y autonomía, correspondiente al ámbito desarrollo personal y social que consiste en “expresar sus emociones y sentimientos autorregulándose en función de las necesidades propias, de los demás y las normas de funcionamiento grupal" (OA4, N3).

En cuanto a la categoría desarrollo acrítico del ámbito afectivo-social han emergido cuatro subcategorías que representan objetivos de aprendizaje rígidos que reducen las posibilidades afectivas del alumnado. La primera subcategoría fue denominada expresión cerrada de afectos positivos para el BS debido a que incluye objetivos que exigen al alumnado manifestar solamente emociones, actitudes e intereses que favorezcan el bienestar, desvalorizando de esta forma los otros componentes afectivos que producen malestar subjetivo y que también contribuyen al desarrollo personal. Asimismo se niega, al alumnado, la posibilidad de experimentar un afecto distinto al planteado en los objetivos o, simplemente, la posibilidad de no desear expresar sus emociones, pues se entiende que es parte de su intimidad y por consideración ética su expresión debe ser voluntaria. Un primer ejemplo es el siguiente objetivo del núcleo exploración del entorno natural, del ámbito interacción y comprensión del entorno, y que consiste en "manifestar interés y asombro por diversos elementos, situaciones y fenómenos del entorno natural explorando, observando, preguntando, describiendo, agrupando, entre otros" (OA1, N2). Un segundo ejemplo es el objetivo del núcleo corporalidad y movimiento, del ámbito desarrollo personal y social que consiste en "manifestar su agrado, al sentirse cómodo, seguro y contenido corporalmente" (OA1, N1).

La segunda subcategoría se denomina experimentación cerrada de emociones positivas para el $B S$ ya que incluye objetivos que exigen al alumnado sentir cierto tipo de emociones durante sus actividades de aprendizaje, lo cual es totalmente incoherente con la diversidad de subjetividades que existe en un grupo de estudiantes de modo que es una clara reducción, estandarización y simplificación del ámbito afectivo. Un ejemplo es el siguiente objetivo del núcleo lenguaje verbal, correspondiente al ámbito comunicación integral y que consiste en "disfrutar de distintos textos gráficos (libros de cuentos y láminas, entre otros) al manipularlos y observar sus imágenes" (OA7, N1).

La tercera subcategoría se denomina sociabilización cerrada de las emociones porque incluye objetivos que exigen al alumnado comunicar y representar solamente emociones positivas para el BS, lo cual transforma ciertas emociones en una condición obligatoria que se acerca más al adoctrinamiento que a la comprensión emocional. Asimismo, no respeta la diversidad de identidades que existe en los diferentes grupos humanos y ubica al profesorado en una situación que puede generar una exigencia forzosa en torno a las experiencias afectivas de sus aprendices. Este aspecto se presenta en el siguiente objetivo del núcleo identidad y autonomía, correspondiente al ámbito desarrollo personal y social y que consiste en "manifestar satisfacción cuando percibe que adultos significativos le 
expresan afecto" (OA2, N1). Por medio de este análisis no se pretende señalar que es innecesario fomentar las emociones positivas para el BS sino, más bien, que se establezca como patrón obligatorio que los estudiantes deben conseguir. Ante esta exigencia cabe preguntarse lo siguiente: ¿qué sucede si un alumno se encuentra muy agotado y no desea expresar satisfacción? O también, ¿qué sucede si un niño logra adaptarse al entorno educativo con dificultades y tarda en lograr un vínculo afectivo con el profesorado? Tal vez sería más conveniente plantear un objetivo de carácter más amplio o abierto como, por ejemplo, que el alumnado aprenda a manifestar o reconocer lo que siente cuando un adulto significativo le expresa afecto.

La cuarta y última subcategoría se denomina exclusiva valoración del bienestar, ya que solamente se identificaron objetivos que aluden al bienestar subjetivo en forma explícita, desconociendo la importancia de los afectos que producen malestar subjetivo. Un ejemplo es el siguiente objetivo del núcleo corporalidad y movimiento, correspondiente al ámbito desarrollo personal y social y que consiste en "reconocer situaciones en que se siente cómodo corporalmente, manifestando al adulto su bienestar y su interés por mantener estas condiciones" (OA1, N2). Esta inclinación hacia las situaciones marcadas por el placer o la comodidad generará que tanto el profesorado como el alumnado le otorguen mayor relevancia al bienestar y se descuiden importantes aprendizajes en torno al sufrimiento y a la incomodidad, como lo es la tolerancia a la frustración, el aceptar las derrotas en los juegos y el sacrificar la comodidad o el placer personal para contribuir con otras personas o con el medio ambiente.

\section{Discusión y conclusiones}

A partir de los resultados obtenidos se identifica que en las bases curriculares de educación parvularia existen algunos OA socio-afectivos orientados desde una perspectiva crítica o abierta, ya que contextualizan la situación pedagógica y permiten una diversidad de respuestas afectivas-emocionales, dada la complejidad de la configuración subjetiva del alumnado (González, 2009). Esta forma de desarrollar este ámbito es coherente con una interpretación sociocultural que "permite analizar las emociones como parte del sistema social de valores y revelar el valor de expresiones emocionales como indicador de la relación de la persona-agente con los contextos sociales y las herramientas culturales características de estos" (Rebollo, Hornillo y García, 2006, p. 35). Asimismo responde a principios constructivistas de la educación debido a que atender a la subjetividad del alumnado es un aspecto relevante para favorecer la motivación intrínseca de los aprendices la cual como parte del "proceso intrínseco del aprendizaje, implica diseñar el aula como espacio relacional y no solo como espacio centrado en la exposición del profesor y la profesora" (González, 2009, p. 4). Este tratamiento abierto de las emociones también es pertinente para que el profesorado pueda interpretar las situaciones pedagógicas y “enlazar el mundo de las emociones con el mundo de la acción moralmente buena" (Marina, 2005, p. 37). En cuanto a los aportes que tendrían una interpretación crítica de la afectividad en el alumnado preescolar se encontraría la necesaria comprensión del profesorado ante las emociones negativas para el BS de los niños, sobre todo cuando tienen dificultades para desarrollar conductas morales adecuadas, ya que sería algo común dentro de su etapa evolutiva (Kay, 1976; Kohlberg, 1992; Hersh et al., 2002).

En efecto, por medio de un enfoque como el mencionado se estará realizando una educación realista debido a que es común que por múltiples factores originados en la familia -tales como la falta de normas morales o la constante vivencia de conductas morales inadecuadas-, los alumnos se presenten en los centros educativos con problemáticas en torno a su formación psicosocial, por lo que el desarrollo socioafectivo es uno de los 
aspectos más complejos de la educación formal. En otras palabras, "es a través de esta relación temprana como aprendemos a interpretar el mundo y a generar respuestas. Y los adultos deberíamos ser muy conscientes de la importancia de estas primeras relaciones" (Martínez, 2006, p. 28).

Por una parte, de acuerdo con el estudio realizado por Gómez-Garibello y Chaux (2014), es común que los niños en edad preescolar desplieguen comportamientos agresivos tanto físicos como relacionales y uno de los principales factores que explican esta conducta es el control de la ira, que corresponde a una emoción negativa para el BS. Así, los autores indican que "niños y niñas con alto nivel de control de la ira reportado por sus profesoras tienden a tener bajos niveles de agresión física y relacional reportado por sus compañeros" (p. 572). Asimismo, el estudio de Henao y García (2009) manifiesta que para favorecer un adecuado desarrollo emocional en niños en edad preescolar es importante que los padres presenten un equilibro emocional en las relaciones sociales, al mismo tiempo que ejerzan su autoridad para fijar límites en la conducta de sus hijos debido a que un estilo de crianza permisiva no contribuye al autocontrol emocional y, en consecuencia, a la autodisciplina.

Por otra parte también se identificaron otros OA socioafectivos, orientados desde una perspectiva cerrada o estandarizada, en cuanto a las respuestas emocionales, actitudinales o de las preferencias personales. Esta orientación posiciona al BS como una meta deseable en comparación al malestar subjetivo, actuando en desmedro de las emociones negativas para el BS, tal como se plantea en la propuesta de educación que encuentra sus bases en la IE y la psicología positiva (Bisquerra, 2005; Bisquerra et al., 2016; Bisquerra y Hernández, 2017). Esta situación se contradice con una educación que pretende lograr un bienestar personal y social y que trasciende el plano subjetivo, generando así una reducción de las posibilidades pedagógicas debido a que "el rechazo de cualquier experiencia vinculada con emociones negativas, conduce a la desmoralización de las acciones (no importan las acciones en sí sino las emociones que generan en los sujetos) al tiempo que a la infravaloración de las posibilidades humanas" (Prieto, 2018, p. 313).

Por un lado no se puede olvidar que en la educación preescolar el afecto y el cariño son la base de todo trabajo, porque en esta edad los niños deberían estar saliendo de un mundo de afecto y de confianza (como debe ser un núcleo familiar sustentado en relaciones amorosas y por consiguiente, respetuosas), por lo tanto, en esta etapa el profesorado debe velar porque esta transición sea lo más amigable y lo menos traumática posible. Esto se logra entablando relaciones con los niños basadas en el cariño, el buen trato, el afecto, el juego, el sentido del humor y las normas claras. Pero, por otro lado, no todos los niños que asisten a educación parvularia vienen de hogares donde estaban protegidos pues muchos niños provienen de hogares disfuncionales donde han recibido maltrato y falta de cariño. En estos casos hablar de una educación contextualizada, basada en el afecto, es fundamental para aportar a un buen desarrollo personal y social pero se insiste en que no corresponde que este proceso se oriente hacia el adoctrinamiento afectivo y no hacia la comprensión afectiva. Justamente, en relación a la actuación docente frente a los cursos de educación parvularia, el estudio de Triana y Velázquez (2014) manifiesta la importancia de la comunicación asertiva por parte del profesorado con sus estudiantes, para de esta forma favorecer el clima emocional positivo en el aula, ya que las conductas no asertivas estarían asociadas a un clima de aula menos favorable para el aprendizaje. También es preciso mencionar que algunos factores socioculturales, como la pobreza, no son determinantes para que los niños a esta edad desarrollen buenas o malas habilidades sociales, tal como demuestra un estudio realizado en Argentina que identificó que, a pesar 
de las adversidades sociales, hay niños que han logrado "adaptarse a los juegos de otros niños, halagar a sus padres, denunciar cuando otro niño le hace algo desagradable, iniciativa para vincularse con pares no conocidos, comportamientos cooperativos, expresión de sentimientos positivos en sus interacciones con adultos, entre otros" (Betina y Contini, 2009).

A modo de conclusión se plantea que la afectividad del alumnado debería ser interpretada desde perspectivas que consideren el bienestar subjetivo, pero que reconozca la contribución de todos los afectos (positivos y negativos para el BS) que aporten a una positiva actitud y conducta moral, como es la educación en valores. De esta forma se evitará fomentar un discurso hedonista que propicia el actuar individualista o egocéntrico en el alumnado y que deriva en conductas dañinas para el bienestar colectivo tales como las agresiones físicas.

Por último, también se destaca la necesidad de evitar exigir una respuesta afectiva cerrada al alumnado, ya que ante un contenido específico como la literatura, la motricidad o la música, en base a su identidad y por consiguiente a su historial de vida cada alumnado preescolar tiene derecho a sentir múltiples afectos positivos o negativos para el BS que responden a variados factores de la mente consciente e inconsciente. Esto no significa que se desconozcan los beneficios para la memoria, la atención, la motivación y el aprendizaje de las emociones positivas para el BS, sino que consiste en reconocer que las emociones son respuestas afectivas que no se eligen sino que emergen en forma automática, por ende su vivencia no puede ser establecida como objetivo de aprendizaje. Cabe destacar que el hecho de experimentar alegría, diversión o entusiasmo en el aula no dependerá solamente del alumnado preescolar sino que también del contexto pedagógico, lo que incluye el estilo de comunicación del profesorado, el material educativo o la infraestructura del centro educativo. Entonces si algún estudiante no logra disfrutar de las actividades preescolares, no necesariamente se vincula a la capacidad de aprender, de modo que si se desea incluir la afectividad en los OA es preciso enfocarse tanto en la formación moral como en las competencias afectivas referidas a la conciencia, la comprensión o la regulación de los afectos. Así, se reconoce que el profesorado tiene la posibilidad de suscitar emociones morales por medio de la formación moral del alumnado, pero esto es una consecuencia del aprendizaje, o como se decía anteriormente, una respuesta automática a una determinada configuración subjetiva, que se encuentra también mediada por la maduración cognitiva.

\section{Referencias bibliográficas}

Alonso, J. (2017). Las emociones. La base neurológica del comportamiento. Barcelona: RBA.

Betina, A. y Contini, N. (2009). Las habilidades sociales en niños preescolares en contextos de pobreza. Ciencias psicológicas, 3(1), 57-66.

Bisquerra, R. (2003). Educación emocional y competencias básicas para la vida. Revista de Investigación Educativa, 21(1), 7-43.

Bisquerra, R. (2005). La educación emocional en la formación del profesorado. Revista interuniversitaria de formación del profesorado, 19(3), 95-114.

Bisquerra, R. (Coord.) (2016). Educación emocional. Propuestas para educadores y familias. Bilbao: Desclée de Brouwer.

Bisquerra, R. y Hernández, S. (2017). Psicología positiva, educación emocional y el Programa Aulas Felices. Papeles del psicólogo, 38(1), 58-65. 
Bisquerra, R. y Filella, G. (2018). Análisis del vocabulario emocional en el profesorado de lengua. Revista electrónica interuniversitaria de formación del profesorado, 21(1), 161-172. doi: 10.6018/reifop.21.1.298421

Carretero, M. (2000). Constructivismo y educación. Delegación Cuauhtémoc: Progreso.

Coll, C. (1993). Psicología y currículum. Barcelona: Paidós.

Elorrieta-Grimalt, M. (2012). Análisis crítico de la educación moral según Lawrence Kohlberg. Educación y educadores, 15(3), 497-512.

García-Fariña, A., Jiménez, F. y Anguera, M. (2016). Análisis observacional del discurso docente del profesorado de educación física en formación a través de patrones comunicativos. Cuadernos de psicología del deporte, 16(1), 171-182.

Gómez-Garibello, C. y Chaux, E. (2014). Agresión relacional en preescolar: variables cognoscitivas y emocionales asociadas. Universitas Psychologica, 13(2), 565-574. doi: 10.11144/Javeriana.UPSY13-2.arpv

González, F. (2009). La significación de Vygotski para la consideración de lo afectivo en la educación: las bases para la cuestión de la subjetividad. Revista electrónica actualidades investigativas en educación, 9, 1-24.

Guedes, S. y Álvaro, J. (2010). Naturaleza y cultura en el estudio de las emociones. Revista española de sociología, 13, 31-47.

Henao, G. y García, M. (2009). Interacción familiar y desarrollo emocional en niños y niñas. Revista latinoamericana de ciencias sociales, niñez y juventud, 7(2), 785-802.

Hersh, H., Reimer, J. y Paolitto, D. (2002). El crecimiento moral: de Piaget a Kohlberg. Madrid: Narcea.

Kay, W. (1976). El desarrollo moral. Su estudio psicológico desde la niñez hasta la adolescencia. Buenos Aires: El Ateneo.

Kirk, D. y MacPhail, A. (2002). Teaching games for understanding and situaded learning: Rethinking the Bunker-Thorpe Model. Journal of Teaching in Physical Education, 21, 177-192.

Kohlberg, L. (1976). Moral stages and moralization: The cognitive-development approach. En T. Lickona (Ed.), Moral development and behavior: Theory research and social issues (3153). Nueva York: Holt, Rinehart and Winston.

Kohlberg, L. (1992). Psicología del desarrollo moral. Bilbao: Desclée de Brouwer.

Marina, J. (2005). Precisiones sobre la educación emocional. Revista interuniversitaria del profesorado, 54, 27-44.

Martínez, M. (2006). Cómo favorecer el desarrollo emocional y social de la infancia. Hacia un mundo sin violencia. Madrid: Catarata.

Maturana, H. (1996). El sentido de lo humano. Santiago de Chile: Dolmen. 
Maturana, H. y Nisis, S. (1997). Formación humana y capacitación. Santiago de Chile: Dolmen. Ministerio de Educación (2013). Formación en sexualidad, afectividad y género. Santiago. Ministerio de Educación (2018). Bases curriculares educación parvularia. Santiago.

Moreno, A., Gamboa, R., y Poblete, C. (2014). La educación física en Chile: análisis crítico de la documentación ministerial. Revista Brasileira de Ciências do Esporte, 36(2), 411-427.

Moreno, A. (2018). La educación física chilena en educación básica: una caracterización crítica. Journal of the Latin American socio-cultural studies of sport, 9(2), 65-78.

Mujica, F. (2018a). Las emociones en la educación física escolar. El aporte de la evaluación cualitativa. EmásF. Revista digital de educación física, 51, 64-78.

Mujica, F. (2018b). Educar y suscitar emociones en la educación: análisis crítico de su contribución al desarrollo moral. Revista de la Facultad de Educación de Albacete, 33(2), 15-27.

Mujica, F., Inostroza, C. y Orellana, N. (2018). Educar las emociones con un sentido pedagógico: un aporte a la justicia social. Revista internacional de educación para la justicia social, 7(2), 113-127. doi: 10.15366/riejs2018.7.2.007

Mujica, F., Orellana, N. y Canepa, P. (2018). Educación emocional en la asignatura de educación física: análisis crítico del valor positivo o negativo de las emociones. Revista Dilemas contemporáneos: educación, política y valores, 6(1), 1-23.

Murillo, F.J., y Román, M. (2010). Retos en la evaluación de la calidad de la educación en América Latina. Revista iberoamericana de educación, 53, 97-120.

Onwuegbuzie, A., Dickinson, W., Leech, N. y Zoran, A. (2011). Un marco cualitativo para la recolección y análisis de datos en la investigación basada en grupos focales. Paradigmas, 3, 127-157.

Osses, S., Ibañez, F. y Sánchez, I. (2006). Investigación cualitativa en educación. Hacia la generación de teoría a través del proceso analítico. Estudios pedagógicos, 32(1), 119-133.

Prieto, M. (2018). La psicologización de la educación: implicaciones pedagógicas de la inteligencia emocional y la psicología positiva. Educación XX1, 21(1), 303-320. doi: 10.5944/ educXX1.16058

Quintana, J.M. (1995). Pedagogía moral. El desarrollo moral integral. Madrid: Dykinson.

Rebollo, M., Hornillo, I. y García, R. (2006). El estudio educativo de las emociones: una aproximación sociocultural. Teoría de la educación. Educación y cultura en la sociedad de la información, 7(2), 28-44.

Reeve, J. (2010). Motivación y emoción. Santa Fe: McGraw-Hill.

Sarramona, J. (2008). Teoría de la educación. Barcelona: Ariel.

Scheler, M. (2005). Esencia y formas de la simpatía. Salamanca: Sígueme. 
Steinfath, H. (2014). Emociones, valores y moral. Universitas Philosophica, 31(63), 71-96.

Toro, S. (2012). Didáctica de la motricidad, una propuesta desarrollada en rel-acción a la infancia. Estudios pedagógicos, 38(1), 45-57.

Toro, S. y Valenzuela, P. (2012). Desde la acción a la enacción. Más allá del movimiento y de la educación física. Estudios pedagógicos, 38(Esp.), 211-230.

Triana, A. y Velásquez, A. (2014). Comunicación asertiva de los docentes y clima emocional del aula en preescolar. Voces y silencios, Revista latinoamericana de educación, 5(1), 23-41.

Unicef y Unesco (2008). Un enfoque de la educación para todos basado en los derechos humanos. Nueva York: Fondo de las Naciones Unidas para la infancia.

Velázquez, L. (2005). Experiencias estudiantiles con la violencia en la escuela. Revista mexicana de investigación educativa, 10(26), 739-764.

\footnotetext{
Notas

*Facultad de Educación, Universidad Católica de Temuco (Chile).

**Corporación Municipal de Viña del Mar para el Desarrollo Social (Chile).

1 Doctor (Cand.) en Ciencias de la Actividad Física y del Deporte, Universidad Politécnica de Madrid (España). Magister en Ciencias de la Actividad Física y del Deporte, y Profesor de Educación Física, Universidad de Playa Ancha de Ciencias de la Educación (Chile). Investigador, Centro de Investigación Escolar y Desarrollo, Facultad de Educación, Universidad Católica de Temuco (Chile). Investigador en emociones y moral en los procesos educativos.

${ }^{2}$ Educadora de Párvulos, Universidad de Playa Ancha de Ciencias de la Educación (Chile). Docente de preescolar, Escuela Libertador Bernardo O'Higgins (Chile). Orientadora educacional, vocacional y laboral, Pontificia Universidad Católica de Valparaíso (Chile). Investigadora en afectividad y convivencia escolar.
}

\section{Contribución de autoría:}

Los dos autores han realizado en partes iguales la elaboración del artículo. 